\title{
Association of Depression and Anxiety Symptoms with Body Mass Index (for age cut offs) in non-clinical sample of adolescents studying in public schools of Delhi; cross sectional study
}

Preeti Khanna ${ }^{1}$, Bani Tamber Aeri ${ }^{2}$

${ }^{1}$ Senior Research Fellow (PhD Scholar), Department of Food and Nutrition, Institute of Home Economics, University of Delhi, India; ${ }^{2}$ Assistant Professor, Department of Food and Nutrition, Institute of Home Economics, University of Delhi, India

\begin{tabular}{|c|c|c|c|c|c|c|c|c|}
\hline Abstract & Introduction & Methodology & Results & Conclusion & References & Citation & \multicolumn{2}{|c|}{ Tables / Figures } \\
\hline \multicolumn{9}{|c|}{ Corresponding Author } \\
\hline \multicolumn{8}{|c|}{$\begin{array}{l}\text { Dr. Bani Tamber Aeri, Assistant Professor, Department of Food and Nutrition, Institute of Home Economics, } \\
\text { University of Delhi, India - } 110024 \\
\text { E Mail ID: bani.aeri@ihe.du.ac.in }\end{array}$} & 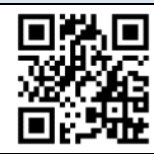 \\
\hline
\end{tabular}

\section{Citation}

Khanna P, Aeri BT. Association of Depression and Anxiety Symptoms with Body Mass Index (for age cut offs) in non-clinical sample of adolescents studying in public schools of Delhi; cross sectional study. Indian J Comm Health. 2020;32(2):386393.

Source of Funding: University Grants Commission Conflict of Interest: None declared

\section{Article Cycle}

Received: 27/04/2020; Revision: 09/05/2020; Accepted: 25/05/2020; Published: 30/06/2020

This work is licensed under a Creative Commons Attribution 4.0 International License.

\section{Abstract}

Objectives: The present study was designed with the objective to study the prevalence of depression and anxiety symptoms among adolescents and to explore the association of these disorders with Body Mass Index. Settings and Design: School setting and Cross-Sectional study design. Participants: 546 adolescents, aged 13-15 years, studying in public schools $(n=5)$ in Delhi (Purposive sampling). Methods and Material: Anthropometric measurements: Height of the subjects was measured using a stadiometer in $\mathrm{cm}$ (to nearest $0.5 \mathrm{~cm}$ ). Weight was assessed using TANITA's Body Fat Monitor (UM-076). After gathering height and weight data, BMI $(\mathrm{kg} / \mathrm{m} 2) \mathrm{Z}$ scores were calculated and classified into four categories: Underweight, Normal weight, Overweight and Obesity based on WHO's growth standards for BMI for age cutoffs. Mental Health Assessment: For this purpose, we used the Child Behavior Checklist (CBCL) for ages 6-18 years; parent report version. Results: A $V$ shaped curve (trend) was observed between the association of depression and anxiety scores in four BMI categories; with majority of the malnourished adolescents having higher scores for depression and anxiety symptoms. It was interesting to note that any deviation from normal weight, either underweight or overweight/obese was significantly associated with depression $(p=<0.001)$ and anxiety $(p=<0.001)$ scores. Conclusions: The study emphasizes the association between body weight and depression and anxiety symptoms among adolescents studying in public schools of Delhi. It adds to the growing body of research in the area of nutritional psychiatry which needs to be promoted for the prevention and management of these disorders through a healthy diet.

\section{Keywords}

Adolescent; Depression; Anxiety; Malnutrition; BMI; Mental health

\section{Introduction}

India is a home to more than 243 million adolescents and by 2020 it will be a country with the highest percentage of this age group in its population. (1) "Adolescence" is a transitional, most rapid and formative developmental human life phase. Adolescent wellbeing is based on positive physical, sexual, neurological and psychosocial health and development. $(1,2)$

A major task in adolescence is getting comfortable with a body that is rapidly changing. Failure to adapt to new changing body features and dissatisfaction with body image may be indicators of or factors in the development of mental health issues. Body dissatisfaction, characterized by underweight, overweight and obesity, has been shown to be correlated with Body Mass Index (BMI) in adolescents. Data indicates that depression and anxiety symptoms are a common consequence of starvation (among people with or without eating disorders) and are highly correlated with weight and body image disturbances (3). According to American Psychiatric Association (4) eating problems (eating too much or eating too little) and changes in physical activity 
(increased or decreased) both constitute core symptoms of a major depressive disorder. $(5,6)$

Prospective studies examining childhood mental health and later onset weight gain have generally found an association of weight gain with various mental health and behavioural issues, including an association with behaviour disorders among 8-11 year olds (7), major depression among 6-17 years (8), depressive symptoms prior to 17 years of age (9) and increasing weight and anxiety disorder in adolescent females (10). Longitudinal studies have also evaluated depression as a risk factor for obesity later in life and concluded that depression in youth is positively associated with increased BMI during adulthood (11). On the other hand longitudinal study conducted by Anderson (12) et al (2007) on adolescents concluded that adolescent obesity predicted an increased risk for major depression disorder in adult females over a period of 20 years indicating that weight gain may lead to poor mental health outcomes. A cross sectional study conducted on a sample of 43,534 individuals, aged 18-90 years reported a very significant U-shaped association between BMI and depression. Thus, not only obesity but underweight too was significantly associated with depression (13).

\section{Aims \& Objectives}

1. To assess the BMI of adolescents and

2. To find out the association of body weight with depression and anxiety symptoms among these adolescents studying in public schools of Delhi.

\section{Material \& Methods}

\section{Study Type: Cross sectional study}

Study Population: The study participants comprised of a sample of 546 adolescents, aged $13-15$ years, studying in public schools $(n=5)$ of Delhi. Subjects from VII, VIII \& IX grade were enrolled for the study (Figure 1).

Study Area: Public schools in Delhi

Study Duration: Data were gathered from Jan to Dec 2017 Sample size calculation: The sample size was statistically computed on the basis of prevalence of overweight and obesity among adolescents studying in public \& private schools of Delhi (14); considering 95\% confidence interval, relative precision of $5 \%$ and dropout rate of $10 \%$.

Inclusion - Exclusion Criteria: Both male and female adolescents, aged 13-15 years, who were willing to participate during the entire period of the study and whose parents had given a written consent were enrolled.

Data collection, Measures and Tools: Information about socio-demographic profile was gathered using pre-tested interview cum questionnaire schedule from the subjects. This was followed by anthropometric (height and weight) and mental health assessment (depression and anxiety symptoms) of the subjects. For the assessment of mental health, parents of the subjects were interviewed. (Figure 1)
Anthropometric measurements: Height of the subjects was measured using a stadiometer in $\mathrm{cm}$ (to nearest $0.5 \mathrm{~cm}$ ). While measuring the height, the subjects were standing straight, with their feet together, knees straight and heels, buttocks and shoulder blades were in contact with the vertical wall. Chin was held firmly to maintain the Frankfurt plane (an imaginary line joining the targus of the ear and corner of the eye). Shoulders were relaxed and arms were hanging loosely at the sides with palms facing the thighs. Subjects were asked to take a deep breath and stand tall to aid the straightening of the spine.

Weight was assessed using TANITA's Body Fat Monitor (UM-076). The scale has a maximum capacity of $150 \mathrm{kgs}$. Subjects were weighed bare foot, with minimal clothing. The subjects were made to stand facing ahead. They were not leaning against or holding any support, while the weight was recorded. Zero error of the weighing scale was checked and the scale was calibrated as per Legal Metrology Act, 2009. To avoid variations, measurement of weight was recorded early in the morning as and when the subjects use to reach the school. They consumed their breakfast before reaching the school.

After gathering height and weight data, Z scores were calculated based on WHO's growth standards (15). BMI for age cut offs were used to classify subjects as < - 2SD: Underweight (equivalent to $\mathrm{BMI}<18.5 \mathrm{~kg} / \mathrm{m} 2$ ), - 1 SD to + $1 \mathrm{SD}$ : Normal weight (equivalent to $\mathrm{BMI}>/=18.5$ to 25.0 $\mathrm{kg} / \mathrm{m} 2$ ), > + 1 SD: Overweight (equivalent to BMI 25 $\mathrm{kg} / \mathrm{m} 2$ ) and > + 2 SD: Obese (equivalent to BMI $30 \mathrm{~kg} / \mathrm{m} 2$ ). Mental Health Assessment: For this purpose, we used the Child Behavior Checklist (CBCL) for ages 6-18 years. The $\mathrm{CBCL}$ was developed in the US and has been translated into 85 different languages including nine Indian languages, using a variety of translation methods (Hindi, Bengali, Gujarati, Kannada, Malyalam, Urdu etc). This was administered to the parents of the subjects. This is a standardized measure of parent-reported behavioral problems, with responses graded on a Likert scale, as 0-2. The responses are then summated as directed by the instrument to yield scores for nine behaviour syndromes. The summation of the responses of some of the individual syndromes yields scores for internalizing behaviors (IS), externalizing behaviors (ES), and overall scores for total behaviour problems (TS). Internalizing behaviors include behaviours such as anxious/depressed, withdrawn/depressed, and somatic problems; and externalizing behaviours include rule-breaking, aggression, and inattention. Higher scores for internalizing behaviors indicate an elevated level of depressive symptomatology (16). In the present study $\mathrm{CBCL}$ 6-18 (ISBN 978-0-938565-73-4) was used and only depression and anxiety scores have been assessed. Prior permissions were taken for the use of this tool from concerned authorities.

Ethical Approval and consent: The study was approved by the Institutional Ethics Committee, Institute of Home 
Economics, University of Delhi, India. Written consent from parents and participants was obtained prior to data collection. At no point were names of schools/participants were disclosed anywhere.

Statistical Analaysis: Statistical analysis was performed using SPSS (Statistical Package for Social Sciences) version 12. Mean and standard deviations were derived for numerical data. Chi-square was used for bivariate analysis and ANOVA was used for pair wise comparison. Prevalence is reported in percentages.

\section{Results}

Out of 546 adolescents, 325 were males and 221 were females studying in VIIth, VIIIth \& IXth grade of the schools. $25 \cdot 86 \%$ of the subjects were 13 years of age, $34.07 \%$ were 14 years of age and $40 \cdot 11 \%$ of the subjects were 15 years of age. BMI of the subjects ranged from $16 \cdot 5-31 \cdot 5 \mathrm{~kg} / \mathrm{m} 2$. Overall prevalence of malnutrition was $50 \cdot 74 \%$, including $21.98 \%$ underweight subjects, $14 \cdot 84 \%$ overweight subjects and $13.92 \%$ obese subjects (Table 1 ).

\section{Prevalence of Depression and Anxiety Symptoms}

Prevalence rates of the depression and anxiety symptoms are represented in (Table 2 ). The overall prevalence of depression and anxiety symptoms was $33.51 \%$ and $27 \cdot 47 \%$ respectively.

$21.24 \%$ of the subjects had borderline depression and $12 \cdot 45 \%$ of the subjects had clinical depression scores. Although a higher percentage of males (18.6\%) were suffering from these symptoms as compared to female (14.83\%) subjects; no significant difference between gender and depression scores of the subjects was observed.

In females, a significant difference was observed between age and depression scores ( $p=0.012$ ) but in males no significant difference was observed.

$13.7 \%$ of the subjects had borderline anxiety and $13 \cdot 7 \%$ of the subjects had clinical anxiety scores. A higher percentage of females (14.6\%) were suffering from these symptoms as compared to male $(12 \cdot 82 \%)$ subjects $(p=$ 0.003).

Again, in females a significant difference was observed between age and anxiety scores $(p=0.001)$ but in males no significant difference was observed as far as age is concerned.

Association of depression scores and BMI for age cut offs It was interesting to note that borderline symptoms of depression were visible in underweight (47.5\%), overweight and obese (72.14\%) subjects (Table 3). Further clinical depression was also seen not only in obese and overweight $(46.41 \%)$ subjects but also in underweight $(18.33 \%)$ subjects. On the other hand subjects in normal weight category apparently had better mental health outcomes in terms of lower depression scores with only $1.12 \%$ belonging to borderline symptoms category and $2.97 \%$ showing clinical depression symptoms (Figure 2).
The bivariate association between depression categories and BMI for age cut offs was highly significant $(<0.0001)$. To further verify this association, a pair wise analysis using ANOVA was conducted. There was a significant difference between the depression scores of the subjects in the normal weight category and underweight and overweight/obese category. Again, it is very interesting to note that any deviation from normal weight (Figure 1), either underweight or overweight/obese was significantly associated with depression scores. Mean scores for depression in underweight, overweight and obese categories were $64.37,62.87$ and 64.15 respectively as compared to 55.95 in case of normal weight subjects.

Association of anxiety scores and BMI for age cut offs Similar trend of distribution as observed with depression scores was also observed for anxiety scores and BMI for age cut offs (Table 4). Borderline symptoms were visible in underweight (29.17\%), overweight and obese (43.52\%) subjects. Further clinical anxiety was seen not only in obese and overweight (48.55\%) subjects but also in underweight $(24 \cdot 17 \%)$ subjects. On the other hand subjects in normal weight category apparently had better mental health outcomes in terms of lower anxiety scores with only $2.24 \%$ belonging to borderline symptoms and 2.6\% showing clinical anxiety symptoms (Figure 3 ).

Mean scores for anxiety in underweight, overweight and obese categories were $63.23,60.07$ and 65.48 respectively as compared to 55.82 in case of normal weight subjects (Table 4).

The bivariate association between anxiety scores and BMI for age cut offs was highly significant $(p<0.001)$, therefore, to further verify this association, a pair wise analysis using ANOVA was conducted and similar trend of association was also observed for anxiety scores and BMI for age cut offs as well.

\section{Discussion}

The present study highlights the growing concern regarding the association of physical and mental wellbeing of adolescents in Delhi. As per the India State-Level Disease Burden Initiative Mental Disorders Collaborators (17) (2019) report, in 2017 one in seven Indians were affected by mental disorders of varying severity, including depression and anxiety. In the present study also a high prevalence of depression and anxiety symptoms i.e. $33.51 \%$ and $27.47 \%$ respectively was reported among adolescents, aged $13-15$ years.

In the recent Comprehensive National Nutrition Survey (CNSS, 2019) (18) report, in India 24\%, $4 \%$ and $1 \%$ adolescents, have been reported as underweight, overweight and obese respectively. More than $12 \%$ of adolescents in Delhi were reported to be overweight. BMI is an assessment of nutritional status, which is impacted by food intake. An individual's food intake further impacts his/her brain development \& mental health status. As depicted in (Figure 2) and (Figure 3), in the present study, 
a $V$ shaped curve (trend) was observed between the association of depression and anxiety scores and four BMI for age cut offs; with majority of the malnourished adolescents having higher scores for depression and anxiety symptoms. Depression and anxiety symptoms were reported both among underweight and overweight/obese subjects and any change in weight status from normal weight to either underweight, overweight and obesity was significantly associated with both depression and anxiety symptoms. This is a cause of concern as our study highlighted quite a high prevalence of depression and anxiety symptoms among the subjects. In line with the present study, several other researches $(8,12)$ have also shown that higher BMI may affect and increase the risk of depression. These studies have attributed this association to the biological mechanisms such as inflammation, hormonal system disorder and the risk of somatic diseases which may lead to secondary effects on the mental health status of young adolescents. In the present study it was also observed that in females, a significant difference was found between age and depression and anxiety scores but in males no significant difference was observed. Similar findings have also been reported by other research literature as well, which showed that gender is not a risk factor for depression in childhood, however increasing age and reaching adolescence can increase depression among females but not in males (19). These gender differences can be attributed to the fact that females and males respond to the same stressors differently, and females are more vulnerable because of the sex differences in biological responses (sex hormones especially estrogen and progesterone), self-confidence and coping (20).

Risk factors like gender, age, socio-economic status, physiological status, physical activity pattern, food habits, dietary intake, nutritional intake, body image, etc. all have an influence on the Body Mass Index (BMI). Similarly, the mental health (depression and anxiety) of an adolescent is influenced by innumerable factors like BMI, physical activity and many other physiological and psychological factors. The objective of the present study was to the explore the link between body weight, BMI for age cut offs and depression and anxiety symptoms among adolescents studying in public schools of Delhi, therefore the discussion focuses on BMI and dietary intake as contributing factors to mental health outcomes. It is beyond the scope of this paper to discuss other factors associated with BMI and mental health status.

The mechanisms linking body mass index and depression are likely to be convoluted, as several studies have indicated that each may induce or worsen the other. Depression could also influence the risk of high body mass index via unhealthy lifestyles as mental illness is associated with physical inactivity and unhealthy diets (21). Likewise, medicines prescribed for some mental illnesses might lead to weight gain (22). Prospective evidence of the link between obesity and anxiety disorders is, however, scarce and mixed.

A poor-quality diet (which is lacking in nutrient dense foods but is high in calories) may lead to weight gain as well as nutrient deficiencies that are associated with mental health disorders. For example, depressive and anxiety disorders are inversely linked with dietary intakes of zinc, folate and magnesium and omega -3 fatty acids (23). Dietary intake may also directly impact various biological systems \& mechanisms that underpin depression (oxidative processes, functioning of immune system, levels of salient brain proteins). Research suggests that markers of systemic inflammation are often significantly higher in patients with depression in comparison to the controls indicating dysregulation of immune system (24). Studies have indicated that these inflammatory markers are positively correlated with components of a poor diet. Thus, a healthy diet is associated with reduced inflammation.

Research suggests that high-fat, high sugar diets can affect the brain proteins (signalling molecule 'brain-derived neurotrophic factor' involved in brain development). Brain derived neurotrophic factor is reduced in patients with depression. When it's synthesis is increased, symptoms of depression improve (25). Consistent evidence has concluded that higher quality diets (rich in nutrient dense foods) and diets high in refined carbohydrates and saturated fats are independently related to depression, suggesting possibility of different pathways (26).

Research also indicates that high BMI may affect the risk of suicide directly. This may be due to the effect of high BMI on several hormones such as testostrone, neurotransmitters such as leptin as well as the serotonin levels. Since depression and other mental diseases are strong risk factors for suicide, their assessment and their association with BMI are very important (27). Disentangling the causal nature of these associations is important as malnutrition and common mental illness such as anxiety and depression constitute major public health challenges.

Findings of our study suggest that there may be a possible link between malnutrition and mental health which can be assessed by estimating the BMI of the adolescents. This may provide a non-intensive screening method and preventative strategies can be worked upon to combat this public health problem.

\section{Strengths}

Standardized tools and pre tested questionnaires were used for data collection. This study adds to the growing body of evidence which highlights the association of BMI and mental health disorders among adolescents.

\section{Conclusion}

Our results suggest that, not only obesity but undernutrition too is associated with poor mental health 

outcomes. Therefore, when addressing adolescent malnutrition issues, mental health problems also need to be addressed; the comorbidity of these conditions (mental health problems and malnutrition) may hinder any efforts at achieving a positive health outcome. Given that the relationship between mental health problems and adolescent weight issues differ according to gender group, public health programs that target adolescents should be cognizant of potential comorbid mental health problems.

\section{Recommendation}

Longitudinal intervention strategies are needed to make an impact on the comorbid problems of child malnutrition and psychosocial issues. Addressing both of these comorbidities from a healthy-lifestyle approach appears to be both feasible and effective and requires interprofessional collaboration. Broad-based conceptualization of these issues is necessary for strategically aligned intervention that should occur at the individual, family, school, community, and policy levels.

\section{Limitation of the study}

Since it is cross sectional study we could not explore the onset, causality and reciprocal relationship between BMI categories and mental health disorders. Longitudinal studies are needed to examine the course of depression and possible effect of BMI. Mental health disorders appear in different episodes during life span, so data is required on the life time prevalence $\&$ association.

\section{Relevance of the study}

Findings of our study suggest that there may be a possible link between malnutrition and mental health which can be assessed by estimating the BMI of the adolescents. This may provide a non-intensive screening method and preventative strategies can be worked upon to combat this public health problem.

\section{Authors Contribution}

PK: collected the data, drafted, revised, updated and finalised the manuscript. BTA: drafted, reviewed, updated and finalised the manuscript.

\section{Acknowledgement}

The authors would like to acknowledge the financial assistance provided by University Grants Commission (UGC, India; in the form of PhD scholarship) in the successful completion of this study. They would also acknowledge the participation of the young school going adolescents and their parents and the support provided by the school authorities for successful completion of the study.

\section{References}

1. UNICEF. Adolescence: An Age of opportunity. The state of the world's children 2011. New York; 2011.

2. WHO. Health for the world's adolescents a second chance in the second decade: Summary. Geneva; 2014.
3. Smolak L. Body image in children and adolescents: where do we go from here?. Body Image. 2004 Jan;1(1):15-28. doi: 10.1016/S17401445(03)00008-1. PubMed PMID: 18089138.[PubMed].

4. American Psychiatric Association. Diagnostic and Statistical Manual of Mental Disorders (Fifth ed.). Arlington, VA: American Psychiatric Publishing; 2013. pp. 5-25.

5. Anderson SE, Cohen P, Naumova EN, Must A. Association of depression and anxiety disorders with weight change in a prospective community-based study of children followed up into adulthood. Arch Pediatr Adolesc Med. 2006 Mar;160(3):285-91. doi: 10.1001/archpedi.160.3.285. PubMed PMID: 16520448. [PubMed].

6. Anderson SE, Cohen P, Naumova EN, Must A. Relationship of childhood behavior disorders to weight gain from childhood into adulthood. Ambul Pediatr. 2006 Sep-Oct;6(5):297-301. doi: 10.1016/j.ambp.2006.06.002. PubMed PMID: 17000421.[PubMed]

7. Lumeng JC, Gannon K, Cabral HJ, Frank DA, Zuckerman B. Association between clinically meaningful behavior problems and overweight in children. Pediatrics. 2003 Nov;112(5):1138-45. doi: 10.1542/peds.112.5.1138. PubMed PMID: 14595059.[PubMed].

8. Pine DS, Goldstein RB, Wolk S, Weissman MM. The association between childhood depression and adulthood body mass index. Pediatrics. 2001 May;107(5):1049-56. doi 10.1542/peds.107.5.1049. PubMed PMID: 11331685.[PubMed].

9. Hasler G, Pine DS, Kleinbaum DG, Gamma A, Luckenbaugh D, Ajdacic V, Eich D, Rössler W, Angst J. Depressive symptoms during childhood and adult obesity: the Zurich Cohort Study. Mol Psychiatry. 2005 Sep;10(9):842-50. doi: 10.1038/sj.mp.4001671. PubMed PMID: 15838533.[PubMed]

10. Goodman E, Huang B. Socioeconomic status, depressive symptoms, and adolescent substance use. Arch Pediatr Adolesc Med. 2002 May;156(5):448-53. doi: 10.1001/archpedi.156.5.448. PubMed PMID: 11980549.[PubMed]

11. Richardson LP, Davis R, Poulton R, McCauley E, Moffitt TE, Caspi A, Connell F. A longitudinal evaluation of adolescent depression and adult obesity. Arch Pediatr Adolesc Med. 2003 Aug;157(8):739-45. doi: 10.1001/archpedi.157.8.739. PubMed PMID: 12912778. [PubMed].

12. Anderson SE, Cohen $P$, Naumova EN, Jacques PF, Must $A$. Adolescent obesity and risk for subsequent major depressive disorder and anxiety disorder: prospective evidence. Psychosom Med. $2007 \quad$ Nov;69(8):740-7. doi: 10.1097/PSY.0b013e31815580b4. Epub 2007 Oct 17. PubMed PMID: 17942847.[PubMed].

13. Wit L, Straten A, et al. Depression and body mass index, a u-shaped association. BMC Public Health 2009.

14. Arora M, Nazar GP, Gupta VK, Perry CL, Reddy KS, Stigler MH. Association of breakfast intake with obesity, dietary and physical activity behavior among urban school-aged adolescents in Delhi, India: results of a cross-sectional study. BMC Public Health. 2012 Oct 17;12:881. doi: 10.1186/1471-2458-12-881. PubMed PMID: 23075030; PubMed Central PMCID: PMC3549919.[PubMed].

15. de Onis M, Onyango AW, Borghi E, Siyam A, Nishida C, Siekmann J. Development of a WHO growth reference for school-aged children and adolescents. Bull World Health Organ. 2007 Sep;85(9):660-7. doi: 10.2471/blt.07.043497. PubMed PMID: 18026621; PubMed Central PMCID: PMC2636412.[PubMed].

16. Achenbach T.M., \& Rescorla, L.A. (2001). Manual for ASEBA SchoolAge Forms \& Profiles. Burlington, VT: Research Center for Children, Youth \& Families.

17. The burden of mental disorders across the states of India: the Global Burden of Disease Study 1990-2017. Lancet Psychiatry. 2020 Feb;7(2):148-161. doi: 10.1016/S2215-0366(19)30475-4. Epub 2019 Dec 23. PubMed PMID: 31879245; PubMed Central PMCID: PMC7029418. [PubMed].

18. Ministry of Health and Family Welfare (MoHFW), Government of India, UNICEF and Population Council. 2019. Comprehensive National Nutrition Survey (CNNS) National Report. New Delhi.

19. Thapar A, Collishaw S, Pine DS, Thapar AK. Depression in adolescence. Lancet. 2012 Mar 17;379(9820):1056-67. doi: 
INDIAN JOURNAL OF COMMUNITY HEALTH / VOL 32 / ISSUE NO 02 / APR - JUN 2020 10.1016/S0140-6736(11)60871-4. Epub 2012 Feb 2. PubMed PMID: 22305766; PubMed Central PMCID: PMC3488279.[PubMed].

20. Osborn DP, Nazareth I, King MB. Physical activity, dietary habits and Coronary Heart Disease risk factor knowledge amongst people with severe mental illness: a cross sectional comparative study in primary care. Soc Psychiatry Psychiatr Epidemiol. 2007 Oct;42(10):787-93. doi: 10.1007/s00127-007-0247-3. Epub 2007 Aug 24. PubMed PMID: 17721669.[PubMed].

21. Dent R, Blackmore A, Peterson J, Habib R, Kay GP, Gervais A, Taylor V, Wells $G$. Changes in body weight and psychotropic drugs: a systematic synthesis of the literature. PLoS One. 2012;7(6):e36889. doi: 10.1371/journal.pone.0036889. Epub 2012 Jun 15. Review. PubMed PMID: 22719834; PubMed Central PMCID: PMC3376099.[PubMed]

22. Gariepy G, Nitka D, Schmitz N. The association between obesity and anxiety disorders in the population: a systematic review and metaanalysis. Int J Obes (Lond). 2010 Mar;34(3):407-19. doi: 10.1038/ijo.2009.252. Epub 2009 Dec 8. Review. PubMed PMID: 19997072. [PubMed].

23. Miller $\mathrm{AH}$, Raison $\mathrm{CL}$. The role of inflammation in depression: from evolutionary imperative to modern treatment target. Nat Rev
[Association of Depression...] | Khanna P et al Immunol. 2016 Jan;16(1):22-34. doi: 10.1038/nri.2015.5. Review. PubMed PMID: 26711676; PubMed Central PMCID: PMC5542678. [PubMed].

24. Casas, R., Sacanella, E., \& Estruch, R. (2016). The immune protective effect of the Mediterranean diet against chronic lowgrade inflammatory diseases. Endocrine, metabolic \& immune disorders drug targets, 14(4), 245-254 doi:10.2174/1871530314666140922153350

25. O'Neil A, Quirk SE, Housden S, Brennan SL, Williams LJ, Pasco JA, Berk M, Jacka FN. Relationship between diet and mental health in children and adolescents: a systematic review. Am J Public Health. 2014 Oct;104(10):e31-42. doi: 10.2105/AJPH.2014.302110. Review. PubMed PMID: 25208008; PubMed Central PMCID: PMC4167107.[PubMed].

26. Popa TA, Ladea M. Nutrition and depression at the forefront of progress. J Med Life. 2012 Dec 15;5(4):414-9. Epub 2012 Dec 25. PubMed PMID: 23346242; PubMed Central PMCID: PMC3539842.[PubMed].

27. Klinitzke G, Steinig J, Blüher M, Kersting A, Wagner B. Obesity and suicide risk in adults--a systematic review. J Affect Disord. $2013 \mathrm{Mar}$ 5;145(3):277-84. doi: 10.1016/j.jad.2012.07.010. Epub 2012 Aug 4. Review. PubMed PMID: 22871535.[PubMed].

\section{Tables}

\section{TABLE 1 SOCIO-DEMOGRAPHIC PROFILE OF THE STUDY POPULATION}

\begin{tabular}{|c|c|c|}
\hline PARAMETER & CATEGORIES & TOTAL $n=546(\%)$ \\
\hline \multirow[t]{3}{*}{ Age (years) (Mean +/- SD) } & $13+/-0 \cdot 5$ & $141(25 \cdot 86)$ \\
\hline & $14+/-0 \cdot 5$ & $186(34 \cdot 07)$ \\
\hline & $15+/-0.5$ & $219(40 \cdot 11)$ \\
\hline \multirow[t]{2}{*}{ Gender } & Boys & $325(59 \cdot 52)$ \\
\hline & Girls & $221(40 \cdot 48)$ \\
\hline \multirow[t]{3}{*}{ Grade } & VII & $262(47.99)$ \\
\hline & VIII & $113(20 \cdot 7)$ \\
\hline & IX & $171(31 \cdot 32)$ \\
\hline \multirow[t]{4}{*}{ Body Mass Index - Z scores } & $<-2$ SD: Underweight (equivalent to $\mathrm{BMI}<18.5 \mathrm{~kg} / \mathrm{m}^{2}$ ) & $120(21.98)$ \\
\hline & 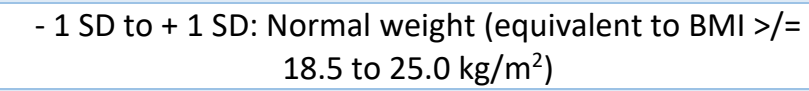 & $269(49 \cdot 27)$ \\
\hline & > + 1 SD: Overweight (equivalent to BMI $25 \mathrm{~kg} / \mathrm{m}^{2}$ ) & $81(14 \cdot 84)$ \\
\hline & > + 2 SD: Obese (equivalent to BMI $30 \mathrm{~kg} / \mathrm{m}^{2}$ ) & $76(13 \cdot 92)$ \\
\hline
\end{tabular}

\section{TABLE 2 PREVALENCE OF MENTAL HEALTH SYMPTOMS AMONG STUDY POPULATION}

\begin{tabular}{|c|c|c|c|c|c|c|}
\hline \multicolumn{5}{|c|}{ Depression Categories } & \multirow[t]{2}{*}{ p valuea } & \multirow[t]{2}{*}{ p valueb } \\
\hline Gender & Age & Normal & Borderline & Clinical & & \\
\hline \multirow[t]{4}{*}{ Boys } & $13(n=93)$ & $61(65 \cdot 59)$ & $17(18 \cdot 28)$ & $15(16 \cdot 13)$ & \multirow[t]{3}{*}{$0 \cdot 168$} & \multirow[t]{8}{*}{$0 \cdot 255$} \\
\hline & $14(n=111)$ & $76(68 \cdot 47)$ & $28(25 \cdot 23)$ & $7(6 \cdot 31)$ & & \\
\hline & $15(n=121)$ & $86(71.07)$ & $23(19 \cdot 01)$ & $12(9 \cdot 92)$ & & \\
\hline & Total $(n=325)$ & $223(68.62)$ & $68(20.92)$ & $34(10.46)$ & & \\
\hline \multirow[t]{4}{*}{ Girls } & $13(n=48)$ & $35(72.92)$ & $6(12 \cdot 5)$ & $7(14 \cdot 58)$ & \multirow[t]{3}{*}{$0 \cdot 012^{*}$} & \\
\hline & $14(n=75)$ & $36(48)$ & $25(33 \cdot 33)$ & $14(18 \cdot 67)$ & & \\
\hline & $15(n=98)$ & $69(70 \cdot 41)$ & $17(17 \cdot 35)$ & $12(12 \cdot 24)$ & & \\
\hline & Total $(n=221)$ & $140(63 \cdot 35)$ & $48(21.72)$ & 33 (14.93) & & \\
\hline \multirow[t]{3}{*}{ Total } & & 363 & $116(21 \cdot 24)$ & $68(12 \cdot 45)$ & & \\
\hline & & \multicolumn{3}{|c|}{ Anxiety Categories } & & \\
\hline & & Normal & Borderline & Clinical & & \\
\hline \multirow[t]{4}{*}{ Boys } & $13(n=93)$ & $64(68 \cdot 82)$ & $12(12 \cdot 9)$ & $17(18 \cdot 28)$ & \multirow[t]{3}{*}{0.05} & \multirow[t]{5}{*}{$0.003 * *$} \\
\hline & $14(n=111)$ & $89(80 \cdot 18)$ & $12(10 \cdot 81)$ & $10(9 \cdot 01)$ & & \\
\hline & $15(n=121)$ & $102(84 \cdot 3)$ & $7(5 \cdot 79)$ & $12(9 \cdot 92)$ & & \\
\hline & Total $(n=325)$ & $255(78.46)$ & $31(9.54)$ & $39(12)$ & & \\
\hline Girls & $13(n=48)$ & $29(60 \cdot 42)$ & $6(12 \cdot 5)$ & $13(27 \cdot 08)$ & $0.001 * *$ & \\
\hline
\end{tabular}




\begin{tabular}{|l|l|l|l|l|}
\hline & $14(\mathrm{n}=75)$ & $38(50 \cdot 67)$ & $21(28)$ & $16(21 \cdot 33)$ \\
\cline { 2 - 5 } & $15(\mathrm{n}=98)$ & $74(75 \cdot 51)$ & $17(17 \cdot 35)$ & $7(7 \cdot 14)$ \\
\cline { 2 - 4 } & Total $(\mathbf{n = 2 2 1})$ & $\mathbf{1 4 1 ( 6 3 \cdot 8 )}$ & $\mathbf{4 4 ( 1 9 . 9 1 )}$ & $\mathbf{3 6 ( 1 6 \cdot 2 8 )}$ \\
\hline \multirow{2}{*}{ Total } & & $\mathbf{3 9 6}$ & $\mathbf{7 5 ( 1 3 . 7 5 )}$ & $\mathbf{7 5 ( 1 3 \cdot 7 5 )}$ \\
\hline
\end{tabular}

$a-p$ value is calculated through Chi-square test to compare the distribution of depression/ anxiety categories between age groups; $b$ - $p$ value is calculated through Chi-square test to compare the distribution of depression/ anxiety categories between gender; ${ }^{*}$ significant at $\mathrm{p}<0 \cdot 05 ;{ }^{*}$ significant at $\mathrm{p}<0.005$

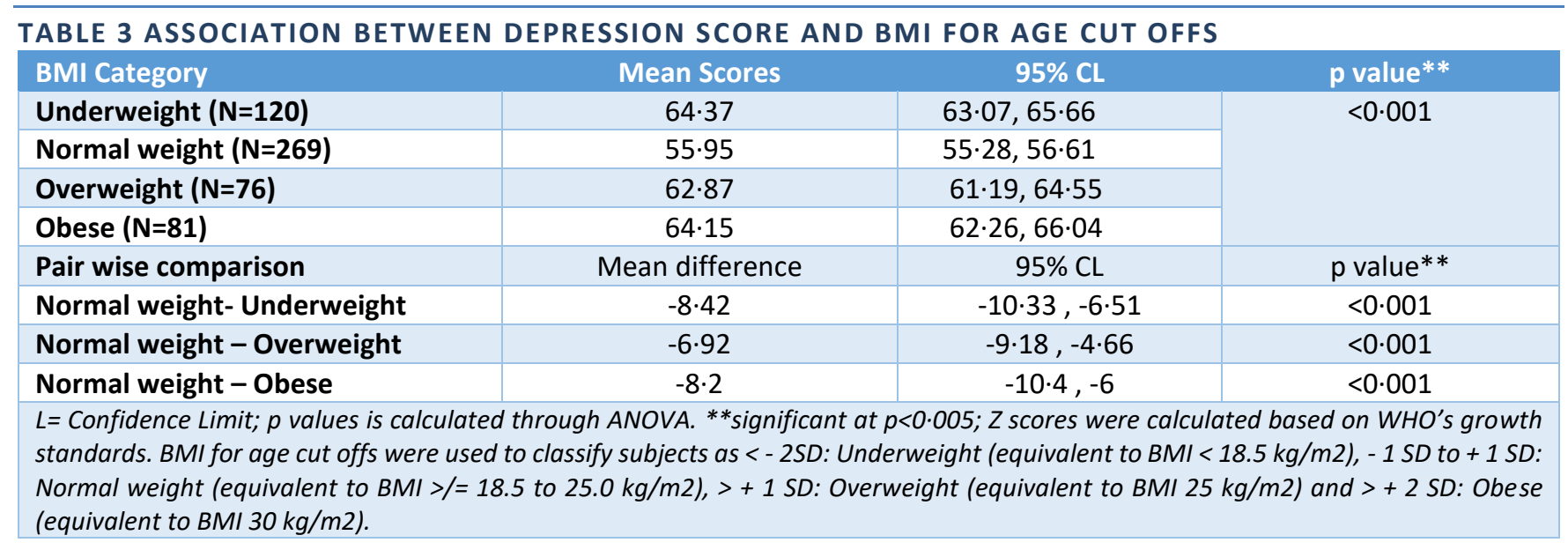

\section{TABLE 4 ASSOCIATION BETWEEN ANXIETY SCORE AND BMI FOR AGE CUT OFFS}

\begin{tabular}{|l|r|r|c|}
\hline Category & Mean & $95 \% \mathrm{CL}$ & p value** \\
\hline Underweight (N=120) & 63.23 & $61 \cdot 75,64 \cdot 72$ & $<0 \cdot 001$ \\
\hline Normal weight (N=269) & 55.82 & $55 \cdot 15,56 \cdot 48$ & \\
\hline Overweight (N=76) & 60.07 & $58 \cdot 52,61 \cdot 61$ & \\
\hline Obese (N=81) & 65.48 & $63 \cdot 21,67 \cdot 75$ & \\
\hline Pair wise comparison & Mean difference & $95 \% \mathrm{CL}$ & $\mathrm{p}$ value** \\
\hline Normal weight - Underweight & -7.42 & $-9 \cdot 47,-5 \cdot 36$ & $<0 \cdot 001$ \\
\hline Normal weight - Overweight & -4.25 & $-6 \cdot 68,-1 \cdot 81$ & $<0 \cdot 001$ \\
\hline Normal weight - Obese & -9.66 & $-12 \cdot 04,-7 \cdot 29$ & $<0 \cdot 001$ \\
\hline Overweight - Obese & -5.42 & $-8.41,-2 \cdot 42$ & $<0.001$ \\
\hline
\end{tabular}

$C L=$ Confidence Limit; $p$ values is calculated through ANOVA. **significant at $p<0.005 ; Z$ scores were calculated based on WHO's growth standards. BMI for age cut offs were used to classify subjects as <- 2SD: Underweight (equivalent to BMI < 18.5 kg/m2), $-1 S D$ to $+1 S D$ : Normal weight (equivalent to BMI >/= 18.5 to $25.0 \mathrm{~kg} / \mathrm{m} 2$ ), > + $1 \mathrm{SD}$ : Overweight (equivalent to BMI $25 \mathrm{~kg} / \mathrm{m2}$ ) and > + $2 \mathrm{SD}:$ Obese (equivalent to $B M 130 \mathrm{~kg} / \mathrm{m} 2$ ) 


\section{Figures}

FIGURE 1 FLOWCHART OF THE STUDY DESIGN

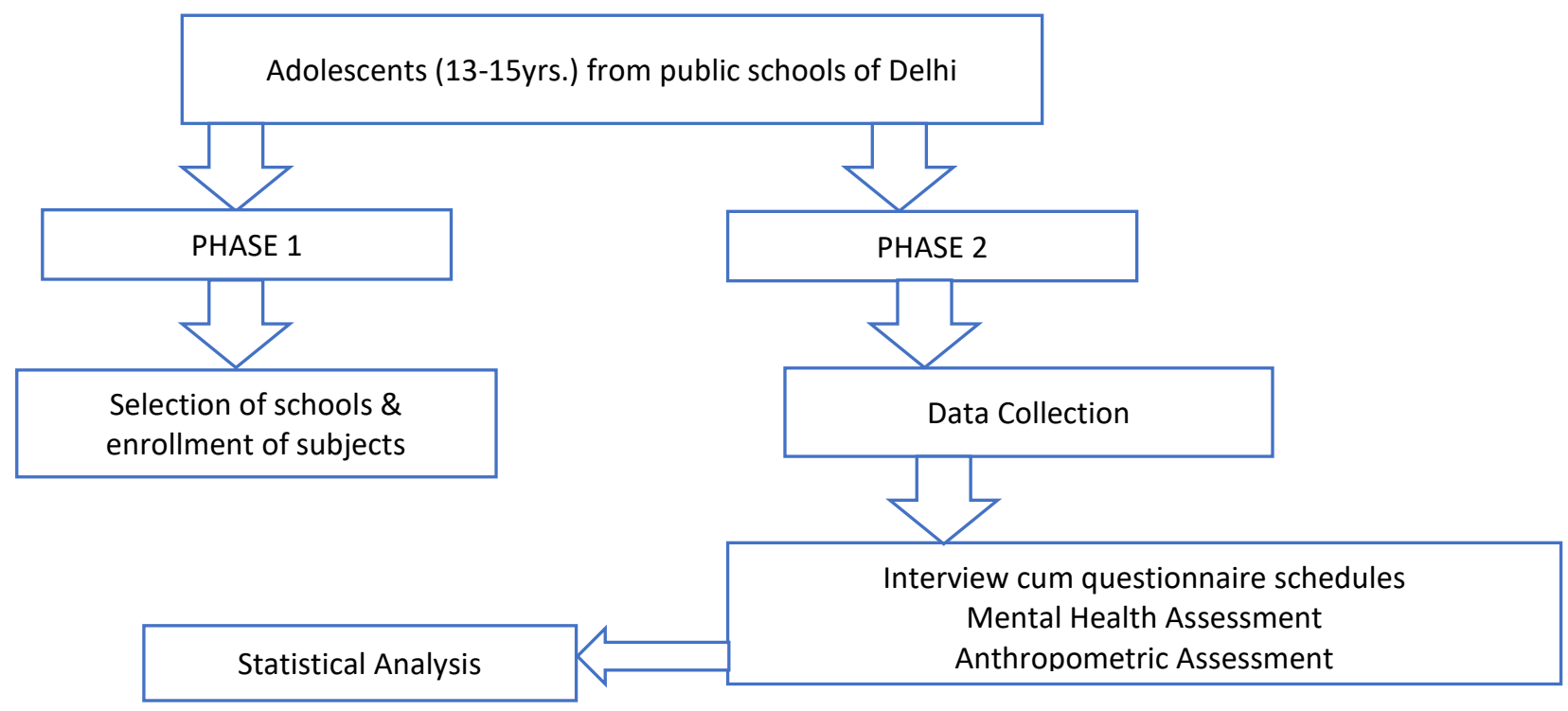

FIGURE 2 ASSOCIATION OF DEPRESSION SCORES WITH BMI FOR AGE CUT OFFS

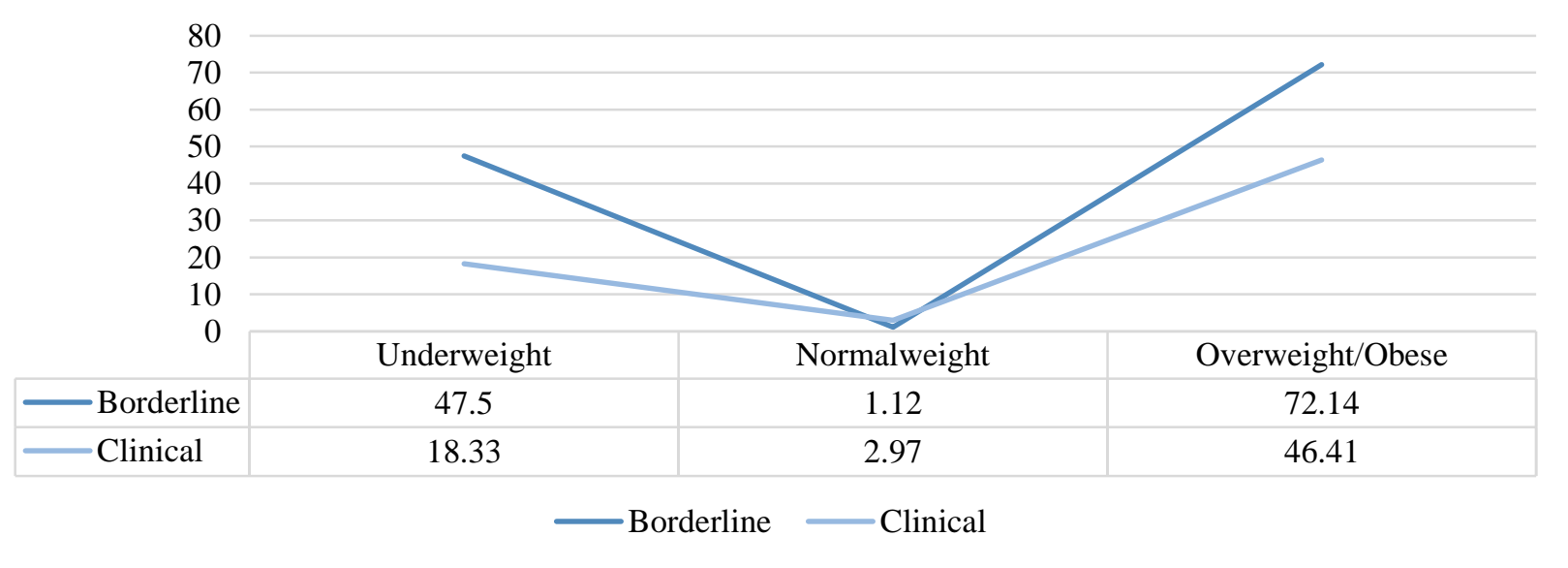

\section{FIGURE 3 ASSOCIATION OF ANXIETY SCORES WITH BMI FOR AGE CUT OFFS}

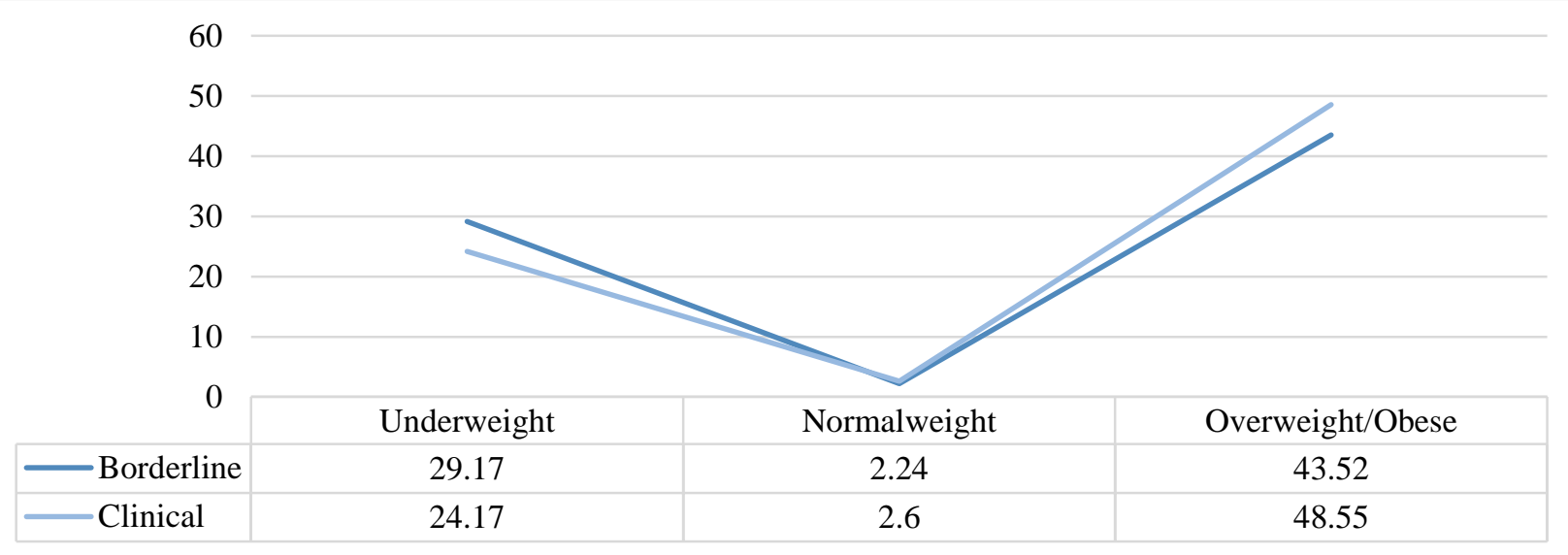

- Borderline Clinical 